\title{
Dedifferentiated Liposarcoma Occurring in the Right Pulmonary Hilum
}

Hirofumi Koike ${ }^{1,2}$, Takeshi Nagayasu ${ }^{3}$, Tomayoshi Hayashi ${ }^{4}$ and Kazuto Ashizawa ${ }^{5}$

Key words: liposarcoma, MRI

(Intern Med 57: 765-766, 2018)

(DOI: 10.2169/internalmedicine.9352-17)

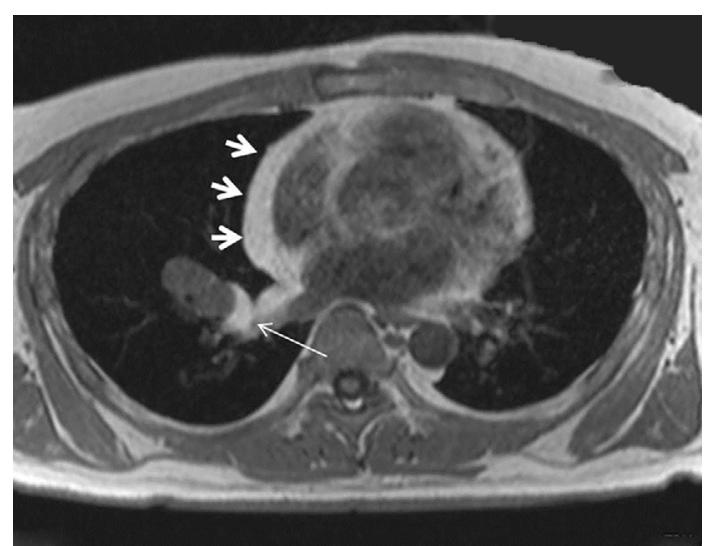

Picture 1.

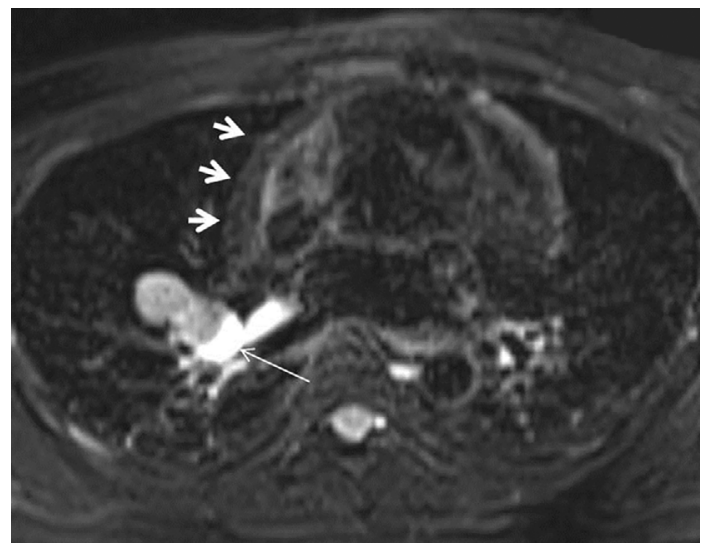

Picture 3.

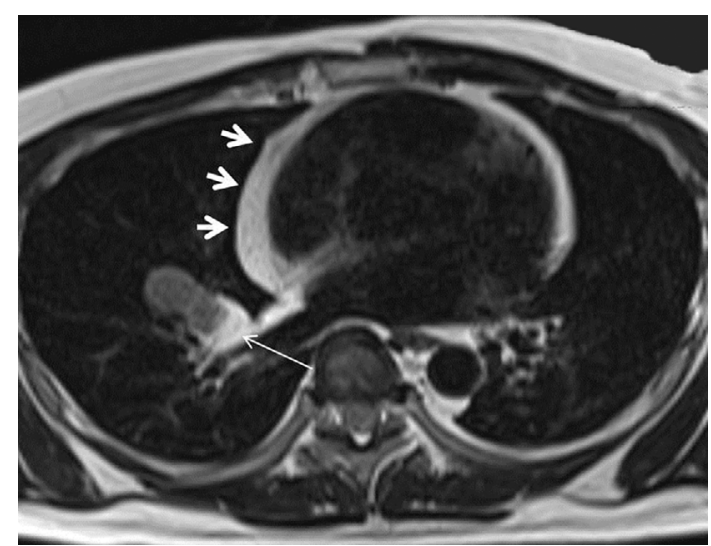

Picture 2.

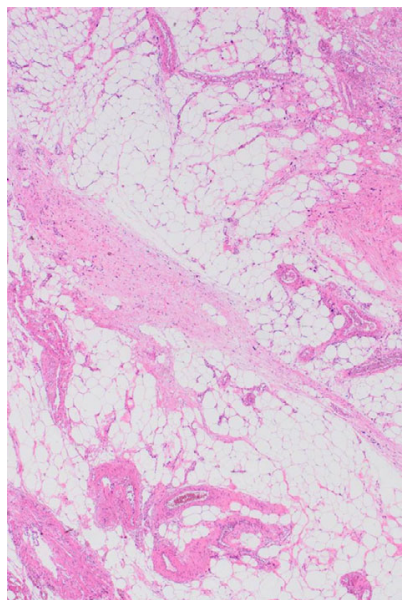

Picture 4.

\footnotetext{
${ }^{1}$ Department of Radiological Sciences, Nagasaki University Graduate School of Biomedical Sciences, Japan, ${ }^{2}$ Department of Radiology, Nagasaki Rosai Hospital, Japan, ${ }^{3}$ Department of Surgical Oncology, Nagasaki University Graduate School of Biomedical Sciences, Japan, ${ }^{4}$ Department of Pathology, Nagasaki Prefecture Shimabara Hospital, Japan and ${ }^{5}$ Department of Clinical Oncology, Nagasaki University Graduate School of Biomedical Sciences, Japan

Received: April 18, 2017; Accepted: June 13, 2017; Advance Publication by J-STAGE: November 20, 2017 Correspondence to Dr. Hirofumi Koike, kei16231623@gmail.com
} 
A few previous reports have presented the imaging findings of mediastinal dedifferentiated liposarcomas $(1,2)$. We herein report a surgically resected case of dedifferentiated liposarcoma occurring in the right pulmonary hilum in a 47year-old asymptomatic man. Magnetic resonance imaging (MRI) showed that the medial part of the lesion (arrow) as well as a prominent pericardial fat pad (arrowheads) had high signal intensity (SI) on both T1-weighted imaging (T1WI) (Picture 1) and T2WI (Picture 2). However, although the SI of the pericardial fat pad (arrowheads) was reduced on fat-suppressed T2WI, the medial part of the lesion (arrow) displayed homogeneous high SI (Picture 3). Pathologically, the lateral part of the lesion was a dedifferentiated liposarcoma component, while the medial part of the lesion was sclerosing-type well-differentiated liposarcoma tissue containing collagen with low cellularity and edematous stroma (Picture 4). MRI might be useful for revealing the malignant potential of the fatty components of a tumor.

The authors state that they have no Conflict of Interest (COI).

\section{References}

1. Coulibaly B, Bouvier C, Payan MJ, et al. Recurrent dedifferentiated liposarcoma of mediastinum involving lung and pleura. Interact Cardiovasc Thorac Surg 9: 741-742, 2009.

2. Hamanaka K, Ohashi M, Nakamura T. Primary mediastinal dedifferenciated liposarcoma resected by lateral thoracotomy with video-assisted thoracoscopic surgery. J Surg Case Rep 1: rjv163, 2016.

The Internal Medicine is an Open Access article distributed under the Creative Commons Attribution-NonCommercial-NoDerivatives 4.0 International License. To view the details of this license, please visit (https://creativecommons.org/licenses/ by-nc-nd/4.0/).

(C) 2018 The Japanese Society of Internal Medicine Intern Med 57: 765-766, 2018 